\title{
Rice black-streaked dwarf virus P6 self-interacts to form punctate, viroplasm-like structures in the cytoplasm and recruits viroplasm-associated protein P9-1
}

\author{
Qian Wang, Tao Tao, Yanjing Zhang, Wenqi Wu, Dawei Li, Jialin Yu, Chenggui Han*
}

\begin{abstract}
Background: Rice black-streaked dwarf virus (RBSDV), a member of the genus Fijivirus within the family Reoviridae, can infect several graminaceous plant species including rice, maize and wheat, and is transmitted by planthoppers. Although several RBSDV proteins have been studied in detail, functions of the nonstructural protein P6 are still largely unknown.

Results: In the current study, we employed yeast two-hybrid assays, bimolecular fluorescence complementation and subcellular localization experiments to show that P6 can self-interact to form punctate, cytoplasmic viroplasmlike structures (VLS) when expressed alone in plant cells. The region from residues 395 to 659 is necessary for P6 self-interaction, whereas two polypeptides (residues 580-620 and 615-655) are involved in the subcellular localization of P6. Furthermore, P6 strongly interacts with the viroplasm-associated protein P9-1 and recruits P9-1 to localize in VLS. The P6 395-659 region is also important for the P6-P9-1 interaction, and deleting any region of P9-1 abolishes this heterologous interaction.
\end{abstract}

Conclusions: RBSDV P6 protein has an intrinsic ability to self-interact and forms VLS without other RBSDV proteins or RNAs. P6 recruits P9-1 to VLS by direct protein-protein interaction. This is the first report on the functionality of RBSDV P6 protein. P6 may be involved in the process of viroplasm nucleation and virus morphogenesis.

\section{Background}

Rice black-streaked dwarf virus (RBSDV), an important pathogen that belongs to the genus Fijivirus in the family Reoviridae, causes rice black-streaked dwarf and maize rough dwarf diseases, which lead to severe yield losses of crops in southeast Asian countries [1-4]. The virus is transmitted to graminaceous plant species via the planthopper Laodelphax striatellus in a persistent, circulative manner [4-6]. Typical symptoms caused by RBSDV include stunting, darkening of leaves and white tumours or black-streaked swellings along the veins on the back of the leaves, leaf blades and sheaths. Microscopy of ultrathin sections has shown that the virions are restricted to the phloem tissues in infected plants

\footnotetext{
* Correspondence: hanchenggui@cau.edu.cn

State Key Laboratory for Agro-biotechnology and Ministry of Agriculture Key Laboratory for Plant Pathology, China Agricultural University, Beijing 100193, P. R. China
}

(C) 2011 Wang et al; licensee BioMed Central Ltd. This is an Open Access article distributed under the terms of the Creative Commons Attribution License (http://creativecommons.org/licenses/by/2.0), which permits unrestricted use, distribution, and reproduction in any medium, provided the original work is properly cited.

and that viroplasms, virus crystals and tubular structures are abundantly synthesized in both infected plants and insect cells $[1,4,7,8]$.

The RBSDV virion is an icosahedral, double-layered particle with a diameter of $75-80 \mathrm{~nm}$ and consists of ten genomic dsRNA segments [9-12]. Protein sequence analysis suggested that $\mathrm{S} 1$ encodes a putative $168.8-\mathrm{kDa}$ RNA-dependent RNA polymerase. S2 and S4 encode a core protein and an outer-shell $\mathrm{B}$-spike protein, respectively $[8,11,12]$. The protein encoded by $\mathrm{S} 3$ is assumed to have some guanylyltransferase activity [13]. Proteins translated from S8 and S10 are the components of the major capsid and outer capsid, respectively $[8,14,15]$. Both S7 and S9 encode nonstructural proteins. S7 ORF1 P7-1 and S9 ORF1 P9-1 are components of the tubular structures and viroplasm produced in infected cells, respectively [8]. Recent studies have demonstrated that P9-1, an $\alpha$-helical protein with a molecular mass of 40 
$\mathrm{kDa}$, self-interacts to form dimers, and it is proposed to be the minimal viral component required for viroplasm formation [16]. P6 is a large nonstructural protein containing 792 amino acids with a molecular mass of 89.6 $\mathrm{kDa}$ that is translated from S6, which is $2645 \mathrm{bp}$ in length and contains a single long ORF. It is synthesized abundantly in RBSDV-infected plants and viruliferous planthoppers [17]. However, further characterization and elucidation of the functions of P6 have not yet been reported.

In this study, we investigated the homologous interaction P6-P6 using a yeast two-hybrid (YTH) assay and bimolecular fluorescence complementation assay (BiFC) and determined the subcellular localization of P6 and P6 derivatives using two different fluorescent markers. P6 self-interacts and forms large discrete viroplasm-like structures (VLS) in plant cytoplasm. The minimal region of P6 necessary for P6 self-interaction in vivo is composed of amino acids residing between positions 395 and 659 . The exact residues in this region that greatly affect the subcellular distribution of P6 were also determined. Furthermore, a strong interaction between P6 and the viroplasm-associated protein P9-1 was apparent from YTH analyses and co-expression experiments. These results might provide deeper understanding of the process of viroplasm formation of RBSDV.

\section{Results}

P6 forms punctate, cytoplasmic viroplasm-like structures in vivo and self-interacts in YTH system

To determine the subcellular localization of $\mathrm{P} 6$, the plasmid expressing P6 fused with green fluorescent protein (GFP) at its C terminus (P6-GFP) was introduced into onion epidermal cells by particle bombardment. Confocal fluorescence microscopy analysis indicated that abundant, punctate viroplasm-like fluorescent foci were observed in the cytoplasm of the onion cells. The bright discrete foci were of different sizes and scattered in the cytoplasm. No apparent fluorescence was visualized in the nuclei. As a negative control, free GFP resulted in a diffuse pattern of fluorescence that was both nuclear and cytoplasmic, which indicated that the moiety GFP does not affect the localization of P6-GFP (Figure 1A). Identical results were observed when the proteins were expressed in the protoplasts of Nicotiana. benthamiana (Additional file 1, Figure S1). This demonstrated that P6 tends to aggregate to form structures that resemble the matrix of the viroplasm when expressed in the absence of other RBSDV proteins, and led us to speculate that P6 might self-associate and be involved in the formation of the viroplasm.

Subsequently, a YTH assay was performed to find out whether P6 had an intrinsic ability to self-interact in vivo. Combinations of plasmids expressing bait protein BD-P6 and prey protein AD-P6 were transformed into Y187 and AH109 strains, respectively. Making sure there was no transcriptional activation or toxicity of BD-P6 for yeast strains, western blot analysis was carried out to verify that both BD-P6 and AD-P6 were expressed in the yeast (data not shown). Cotransformation and yeast mating assays showed that independent yeast colonies containing pGADT7-P6 and pGBKT7-P6 grew well and turned blue in the $\beta$-galactosidase colonylift filter assay (data not shown), indicating that there were strong interactions between P6 molecules. In contrast, no growth was observed for the negative controls (Figure 1B). This suggested that P6 has an inherent ability to self-interact and is able to form VLS when expressed alone in plant cells.

YTH assays indicate the centrally located region spanning residues 395 to 659 is necessary for P6 self-interaction

As there was not much information available from the literature about $\mathrm{P} 6$, protein sequence analysis was performed. BLAST searches indicated that the region approximately inclusive of residues 400 to 675 exhibited limited conservation of amino-acid sequence with the ATPase domain of structural maintenance of chromosomes proteins (SMCs), which play an essential role in chromosome segregation, condensation and organization [18].

In order to determine the region necessary for P6-P6 self-interaction, we sequentially constructed a collection of truncation derivatives that express BD-P6 $6^{98-792}$, BD$\mathrm{P}^{274-792}, \mathrm{BD}-\mathrm{P} 6^{274-703}, \mathrm{BD}-\mathrm{P} 6^{395-703}, \mathrm{BD}-\mathrm{P} 6^{395-659}, \mathrm{AD}-$ $\mathrm{P} 6^{1-449}, \mathrm{AD}-\mathrm{P} 6^{341-792}, \mathrm{AD}-\mathrm{P} 6^{271-703}, \mathrm{AD}^{-\mathrm{P} 6^{274-703}}, \mathrm{AD}-$ $\mathrm{P}^{395-703}$ and $\mathrm{AD}-\mathrm{P} 6^{395-659}$, based on the protein sequence analysis results. Homologous binding capabilities between P6 and these deletions were investigated via the YTH assay. Schematic representation of the different P6 truncations is shown in Figure 2A.

The YTH analysis indicated that a centrally located domain between positions 395 and 659 was required for P6-P6 interaction. All truncations harbouring this region were able to interact with intact P6. However, as their N and $\mathrm{C}$ termini approached this region, the abilities of the P6 mutants to associate with intact P6 decreased. Varying interaction abilities were indicated by the rates of yeast growth on the selective medium. When the deletion comprised exactly the region from positions 395 to 659, the interaction with P6 was very weak, and the colonies transformed with pGADT7-P6 ${ }^{395-659}$ / pGBKT7-P6 or pGADT7-P6/pGBKT7-P6 ${ }^{395-659}$ showed obvious growth inhibition and the streaks turned dark red. Mutant $\mathrm{P} 6^{1-449}$, in which most of the central and C-terminal region was deleted, showed complete 
A
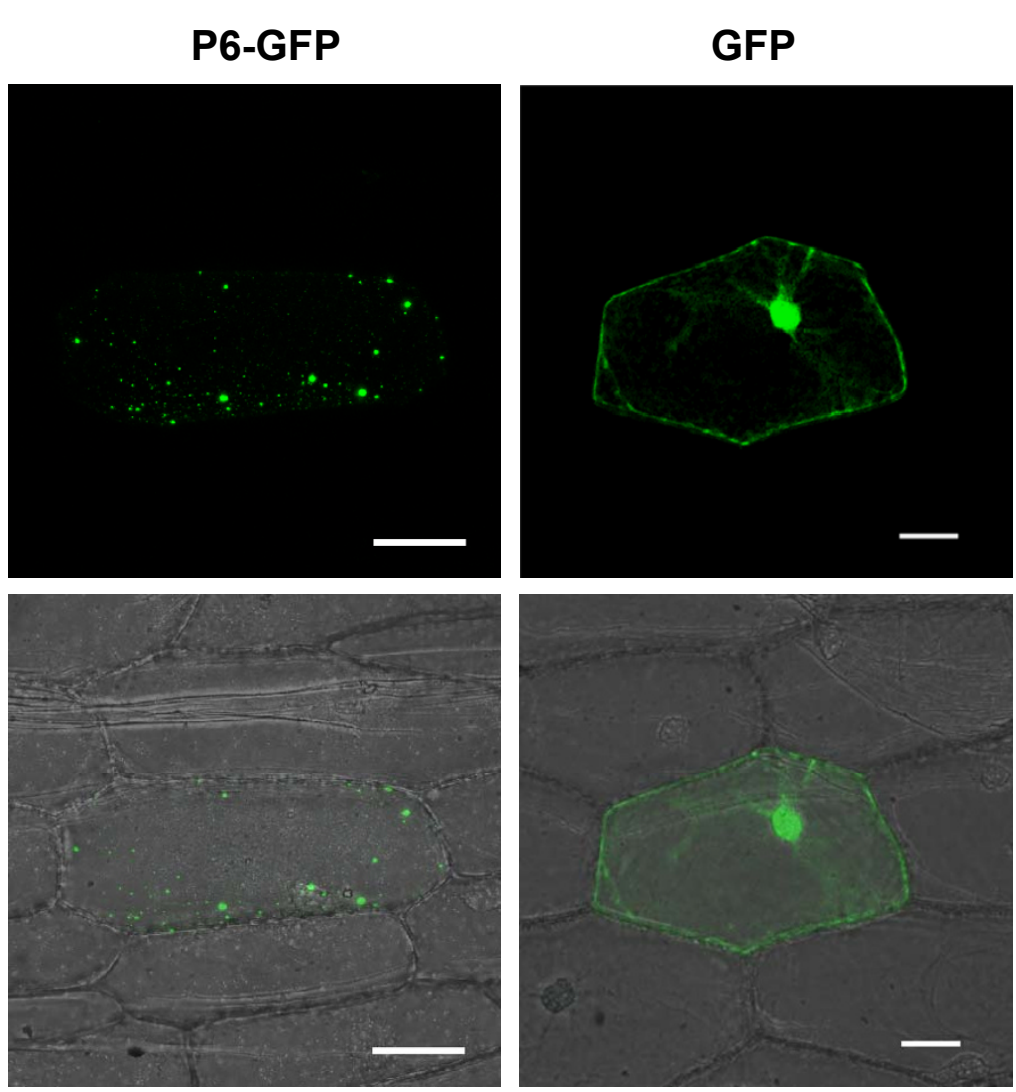

B
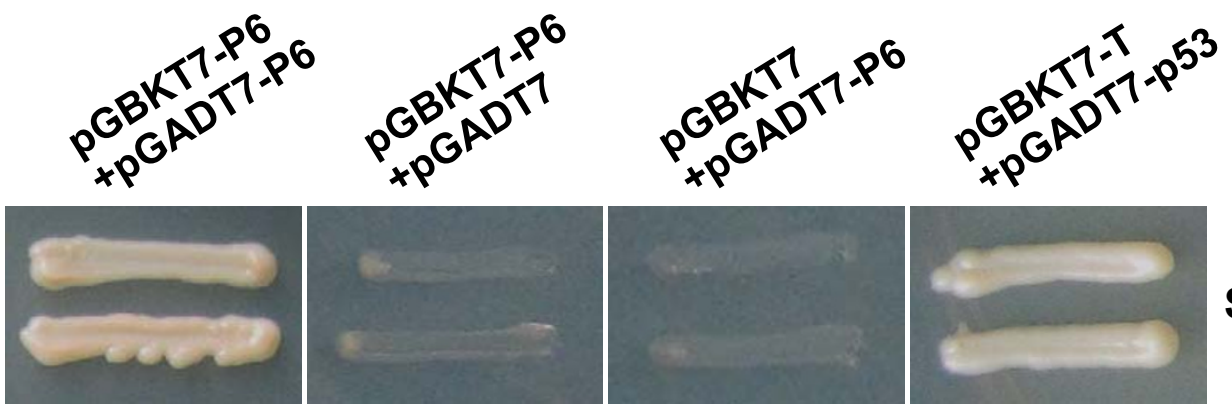

SD/AHWL

Figure 1 P6 forms punctate, cytoplasmic VLS in the onion epidermal cells and self-interacts in YTH system. (A) Subcellular localization of RBSDV P6 fused to GFP and free GFP in onion epidermal cells. Punctata VLS of different sizes were prevalently formed in the onion cells expressing P6-GFP, while diffuse GFP fluorescence was observed in the nucleus and cytoplasm of the cells expressing free GFP. The results were observed 16-24 h after particle bombardment. Bars, $50 \mu \mathrm{m}$. (B) Yeast colonies containing pGBKT7-P6/pGADT7-P6 grew well on the selective medium as did yeast colonies containing pGBKT7-T/pGADT7-p53, which was used as the positive control, whereas yeast transformed with pGBKT7-P6/pGADT7 or pGBKT7/pGADT7-P6 used as negative controls were unable to grow.

inability to interact with P6 (Figure 2B). Binding capabilities between these deletions were also investigated, and the results demonstrated that, even when both the $\mathrm{N}$ and $\mathrm{C}$ termini were absent, the deletions had some ability to associate with each other (data not shown). The results suggested that the region from residues 395 to 659 is necessary to sustain the P6 self-interaction and that further truncation might abolish this interaction.
Transient expression experiments of $\mathrm{P} 6$ derivatives indicate residues 395 to 659 are important for P6 selfinteraction

Recombinant plasmids that can express $\mathrm{P}^{274-792}, \mathrm{P}^{395-}$ 703 and $\mathrm{P}^{395-659}$, fused in-frame to the $\mathrm{N}$ terminus of GFP (P6 $6^{\text {mutant }}-$ GFP) or the $\mathrm{C}$ terminus of DsRed2 (DsRed-P6 ${ }^{\text {mutant }}$ ), were constructed and their subcellular localization was determined. Plasmids expressing 


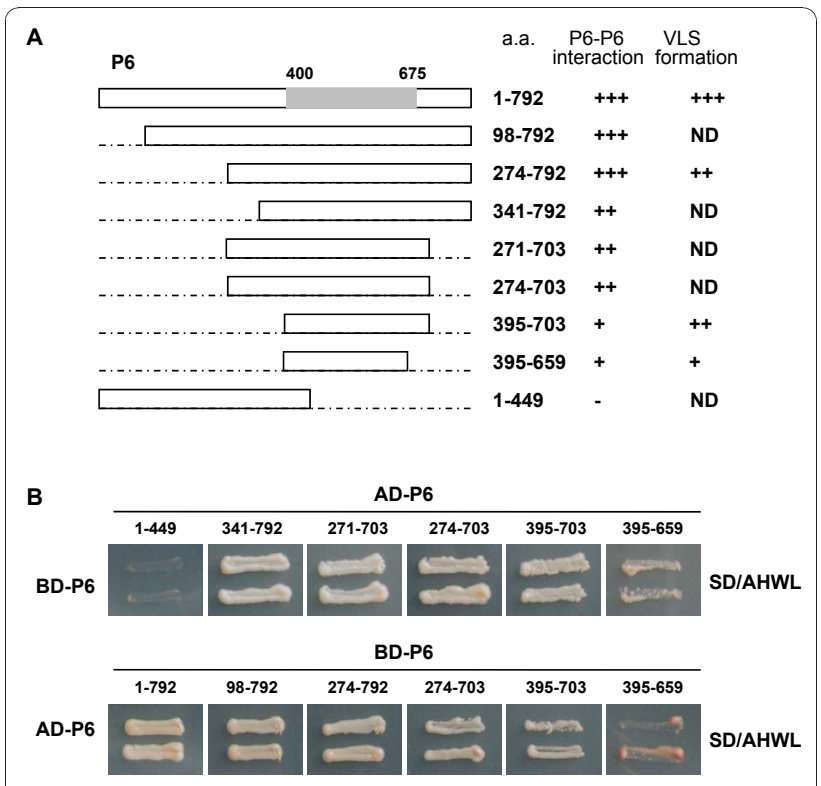

Figure 2 Mapping of the $\mathrm{P} 6$ region involved in $\mathrm{P} 6$ selfinteraction. (A) Schematic representation of P6 and P6 truncations in the study. The full-length P6 (spanning residues 1 to 792) and P6 truncations are indicated by open bars. The P6 domain

(approximately from position 400 to 675) homologous to SMC ATPase is indicated by the gray bar and the deleted regions by the dashed lines. The numbers denote P6 amino acid positions. The ability of P6 truncations to interact with intact P6 in $\mathrm{YTH}$ assays is indicated in the middle ( + , positive; -, negative). The VLS-forming abilities of the different $\mathrm{P} 6$ derivatives are shown on the right $(++$ + , abundant and large $\mathrm{VLS} ;++$, moderate in size and number; + , few in number; -, negative with diffuse distribution; ND, not determined). (B) Homologous interaction between intact P6 and P6 deletions in YTH assays. All truncations harbouring this region were able to interact with intact P6. As their N and C termini approached this region, the interaction ability was decreasing.

P6 ${ }^{\text {mutant }}$-GFP were delivered into onion epidermal cells via biolistic bombardment, whereas those expressing DsRed-P6 ${ }^{\text {mutant }}$ were introduced into epidermal cells of $N$. benthamiana leaves by agroinfiltration assay [19].

Biolistic bombardment experiments indicated that P6 ${ }^{274-792}$-GFP mostly formed large bright discrete foci in the cytoplasm of onion cells, but low levels of diffuse cytoplasmic fluorescence were also observed. P6 $6^{395-703}$ GFP expression resulted in the formation of irregular aggregate-like structures, and minor levels of diffuse GFP signals were also observed at the peripheries of the nuclei, $\mathrm{P}^{395-659}$-GFP resulted in very few (generally less than five) discrete and bright foci in the cytoplasm (Figure 3A). Similar results were obtained when these mutants fused with DsRed2 were expressed in the epidermal cells of tobacco leaves (Figure 3B) or tobacco protoplasts (Additional file 2, Figure S2). Numerous dispersed punctate VLS were detected in the tobacco cells expressing DsRed-P6 $6^{274-792}$, and the expression of DsRed-P6 395-703 and DsRed-P6 $^{395-659}$ resulted in amounts of irregular aggregate-like foci. Weak and uniform red fluorescence signals were present in the cells expressing free DsRed2.

Generally, the fluorescence distribution patterns of the three mutants $\left(\mathrm{P}^{274-792}, \mathrm{P}^{395-703}\right.$ and $\left.\mathrm{P} 6^{395-659}\right)$ indicated that the 395-659 region is important for P6 localization and that self-assembly is possible outside of the P6 native environment. The results also suggested that residues on both sides of the 395-659 region might be engaged in the process, based on the numbers and the size of the fluorescent foci.

\section{Bimolecular fluorescence complementation assay confirms that P6 molecules self-interact in planta}

In order to determine whether P6 molecules self-interact in planta, bimolecular fluorescence complementation assays were carried out (Figure 4). One pair of combinations that can express $\mathrm{P}^{274-703}$ fused either to $\mathrm{YN}$ or $\mathrm{YC}$ was constructed and then delivered into $N$. benthamiana leaves via agroinfiltration. As expected, coexpression of $\mathrm{P}^{274-703}-\mathrm{YN}$ and $\mathrm{P}^{274-703}-\mathrm{YC}$ induced strong recovered YFP signals, which formed numerous tiny fluorescent sites or irregular aggregate-like structures in the cytoplasm. No YFP signals were detected for the negative controls following the co-expression of P6 $6^{274-703}-\mathrm{YN} / \mathrm{YC}$ or $\mathrm{P}^{274-703}-\mathrm{YC} / \mathrm{YN}$. The BiFC assay provided strong evidence that the truncated mutant $\mathrm{P}^{274-703}$ participates in self-interaction so that recovered YFP signals are detected easily in the tobacco cells. From these results, we can confirm that P6 molecules have the ability to self-interact in planta.

\section{Polypeptides consisting of residues 580 to 620 and 615 to 655 are involved in VLS formation}

In light of the results above, it is evident that $\mathrm{P} 6^{395-659}$, which only constitutes one-third of the entire P6 protein, is essential to P6 self-interaction. It is possible that some specific elements in this fragment are responsible for the VLS formation. A P6 motif prediction using MyHits scan http://www.expasy.cn showed that three putative motifs might have relatedness to this interacting region. These three putative motifs are designated pumilio RNA-binding repeat profile, sialic-acid binding micronemal adhesive repeat and intra-flagellar transport protein 57, and they correspond to P6 residues 401-439, 584-608 and 624-654, respectively. In addition, the secondary structure prediction demonstrated that a putative coiled-coil motif might reside in the region from residues 550 to 640 . To determine which motifs might be involved in VLS formation, corresponding derivatives that express P6 ${ }^{\triangle 403-440}$-GFP, P6 ${ }^{\triangle 580-620}$-GFP, P6 ${ }^{\triangle 615-655}$ GFP, DsRed-P6C ${ }^{\triangle 403-440}$, DsRed-P6C $C^{\triangle 580-620}$ and DsRedP6C $\mathrm{C}^{\triangle 15-655}$ were constructed and their subcellular localization was investigated. It is noteworthy that we 


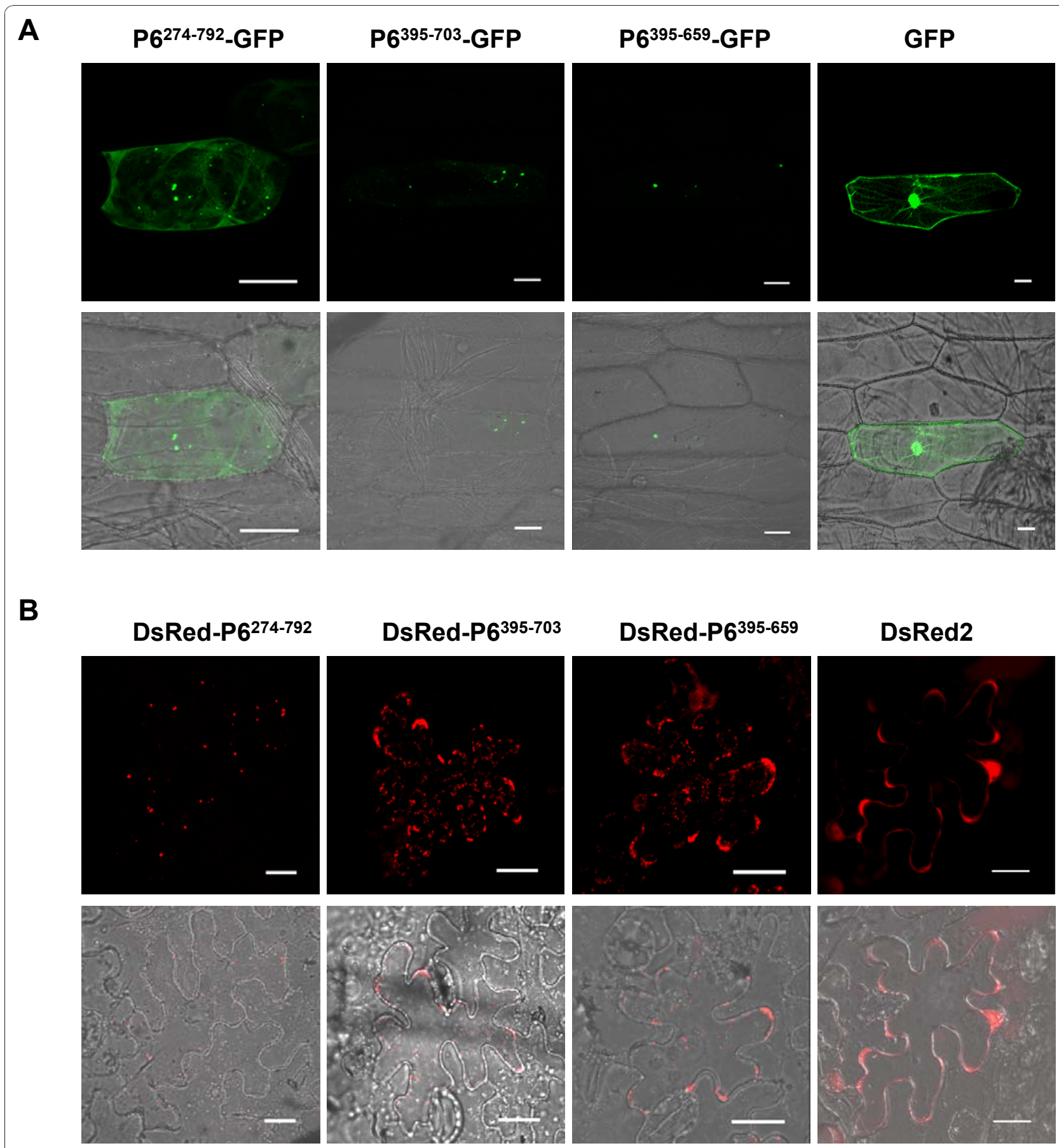

Figure 3 Distribution of P6 truncated versions in planta. (A) Subcellular localization of P6 truncations fused with GFP and free GFP in onion epidermal cells. GFP was excited at $488 \mathrm{~nm}$ and emission was measured at 550-590 nm. Bars, $50 \mu \mathrm{m}$. (B) Subcellular localization of P6 truncations fused with DsRed2 and free DsRed2 in the epidermal cells of $N$. benthamiana leaves. DsRed2 was excited at $543 \mathrm{~nm}$ and emission was measured at 570-600 nm. Bars, $20 \mu \mathrm{m}$. The fluorescence and merged images are depicted in the upper and lower panels, respectively.

did create several plasmids aiming to express intact P6 fused with DsRed2 but failed to detect the fused protein for unknown reasons. Previous results showed that DsRed-P6 ${ }^{274-792}$ was sufficient to induce inclusion bodies, so we created the corresponding mutants
(DsRed-P6C $\mathrm{C}^{\triangle 403-440}$, DsRed-P6C ${ }^{\triangle 580-620}$ and DsRed-

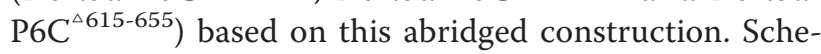
matic representation of the different P6 deletion derivatives is shown in Figure 5. As described earlier, plasmids expressing $P 6^{\text {mutant }}$-GFP were bombarded into onion 

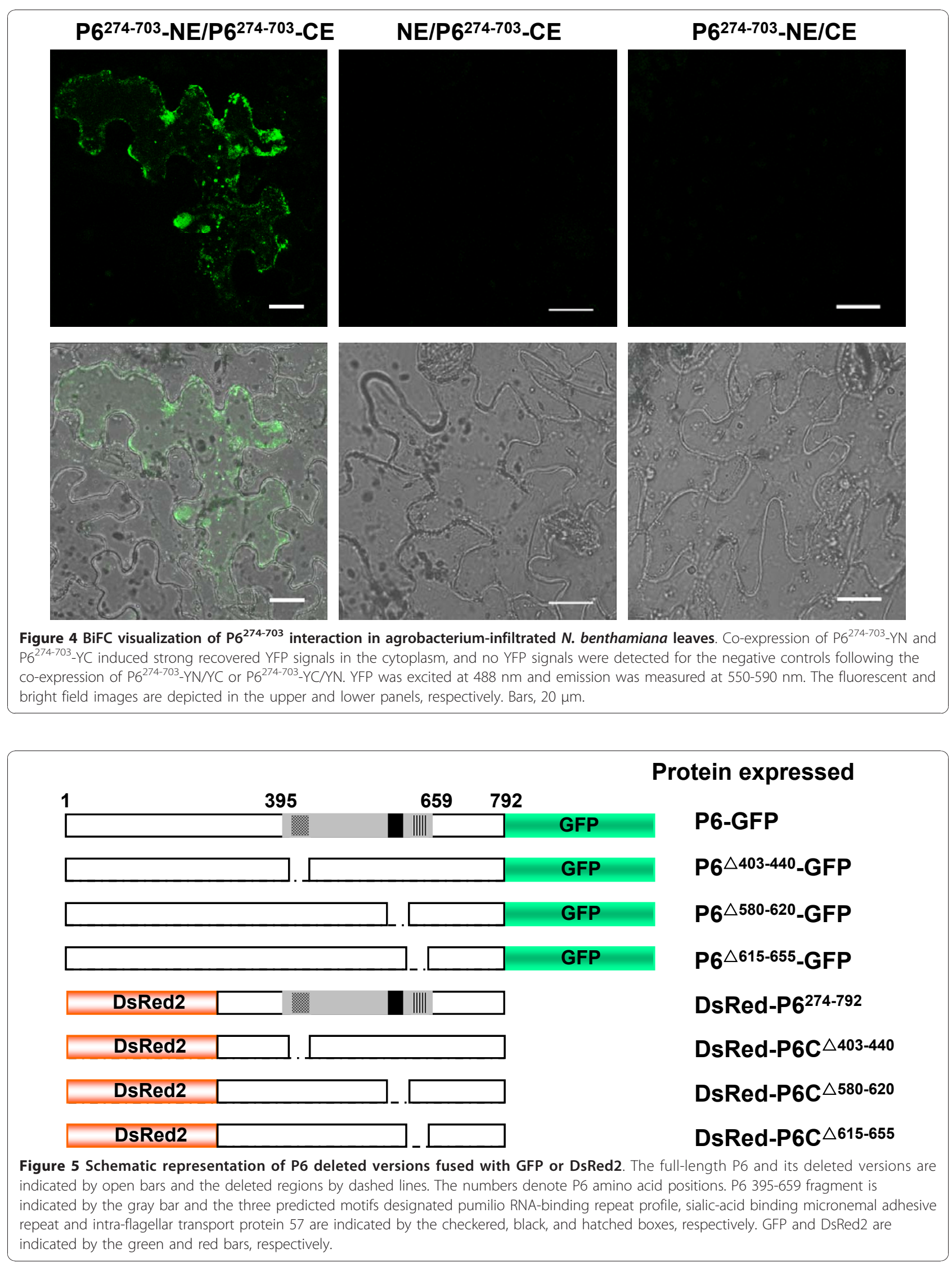
cells, while those expressing DsRed-P6 ${ }^{\text {mutant }}$ were introduced into tobacco leaves by agroinfiltration assay.

Confocal fluorescence microscopy showed that $\mathrm{P}^{\triangle 403-}$

${ }^{440}$-GFP accumulated to form numerous punctate bright foci in the cytoplasm, indistinguishable from those induced by P6-GFP. In contrast, $\mathrm{P} 6^{\triangle 580-620}$-GFP and $\mathrm{P}^{\triangle 615-655}$-GFP distributed throughout the cytoplasm displaying a weaker fluorescence pattern, compared to free GFP, and the fluorescence signals were always visualized at the periphery of the nuclei. Similar results were obtained when P6 mutants were fused with DsRed2. Numerous dispersed punctate aggregates were detected in the tobacco cells expressing DsRed-P6C ${ }^{\triangle 403-}$ ${ }^{440}$, whereas weak and uniform DsRed2 signals were present in the cells expressing either DsRed-P6C ${ }^{\triangle 580-620}$ or DsRed-P6C ${ }^{\triangle 615-655}$. The results are shown in Figure 6.

To sum up, two polypeptide chains, comprising residues 580 to 620 and 615 to 655 , are implicated in VLS formation, and loss of them alters the subcellular localization of P6.

\section{YTH assays demonstrate P6 interacts with P9-1}

Immunoelectron microscopy revealed that antibodies against P9-1 reacted with viroplasm in infected cells [8]. Based on our findings above, P6 likely participates in viroplasm formation. This prompted us to further explore the relationship between P6 and P9-1 via a YTH assay. A plasmid that can express BD-P9-1 was constructed and transformed into Y187 strain. Interestingly, the results showed that there is an intimate association between P9-1 and P6 (Figure 7A). Yeast colonies containing both pGBKT7-P9-1 and pGADT7-P6 grew well on the selective medium, whereas yeast transformed with pGBKT7-P9-1 and pGADT7, which was used as a negative control, was unable to grow. This result indicated that $\mathrm{P} 6$ interacts with $\mathrm{P} 9-1$ in vivo.

\section{P9-1 cannot form inclusion-like structures when expressed alone}

Two plasmids that express P9-1-GFP and DsRed-P9-1 were constructed and bombarded into onion epidermal cells to determine P9-1 subcellular localization. Fluorescence microscopy indicated that both P9-1-GFP and DsRed-P9-1 resulted in a pattern of diffuse and uniform fluorescence distribution in the cytoplasm and nuclei of onion cells, which was a little weaker than that of free GFP or DsRed2 controls (Figure 8A). Our results are inconsistent with the conclusion of Zhang et al that P91 alone aggregates to form inclusion bodies [16]. The same results were obtained when the plasmids were delivered into tobacco protoplasts via polyethylene glycol (PEG) transfection method or introduced into epidermal cells of tobacco leaves by agroinfiltration assay (Additional file 3, Figure S3). Therefore, we consider that P9-1 has a widespread distribution but no ability to aggregate in the cytoplasm when expressed in plant cells on its own.

\section{Colocalization experiments indicate P6 relocalizes the distribution of P9-1 and recruits P9-1 to VLS}

Co-expression experiments were developed to investigate potential P6-P9-1 interactions (Figure 8B). We introduced two plasmids expressing P6-GFP and DsRedP9-1 into onion cells by cobombardment. Contrary to the case when DsRed-P9-1 was expressed alone, when P6-GFP and DsRed-P9-1 were co-expressed, a striking relocalization of red fluorescence emerged. DsRed-P9-1 displayed a nearly complete coincidence with the intracellular distribution of P6-GFP. The two proteins were colocalized and exclusively presented in discrete punctate VLS, identical to those formed by P6-GFP alone, and no diffuse green or red fluorescent signals were observed in the cytoplasm or the nuclei. Control combinations were also investigated to rule out the possibility that GFP or DsRed2 expression might have some aberrant effects on the DsRed-P9-1 or P6-GFP distribution. The colocalization of P6-GFP and DsRed-P9-1 confirmed that P6 has a dramatic effect on the distribution of P9-1 and that it is caused by the direct association between these two proteins.

\section{YTH assays confirm residues 395 to 659 of P6 are necessary for P6-P9-1 heterologous interaction}

Further YTH analyses were performed to examine the regions of $\mathrm{P} 6$ crucial for $\mathrm{P} 6-\mathrm{P} 9-1$ heterologous interaction. $\mathrm{P} 6 \mathrm{AD}$-fused deletions, including $\mathrm{AD}-\mathrm{P} 6^{1-449}, \mathrm{AD}-$ $\mathrm{P}^{341-792}, \mathrm{AD}-\mathrm{P} 6^{274-703}, \mathrm{AD}-\mathrm{P} 6^{271-703}, \mathrm{AD}-\mathrm{P} 6^{395-703}$ and AD-P6 ${ }^{395-659}$, were tested and all P6 deletions except AD-P6 ${ }^{1-449}$ were able to interact with P9-1. Transformants expressing BD-P9-1 and AD-P6 ${ }^{1-449}$ showed no growth on the selective medium, whereas those containing other combinations grew well (Figure 7B). The results indicated that the region located between amino acids 395 and 659 is indispensable for P6-P9-1 interaction.

\section{YTH assays indicate deletion mutants of P9-1 do not interact with P6}

We also investigated P9-1 regions crucial for P6-P9-1 interaction. A dozen P9-1 BD-fused deletions that express fusions BD-P9-1 ${ }^{1-197}, \mathrm{BD}-\mathrm{P} 9-1^{1-207}, \mathrm{BD}-\mathrm{P} 9-1^{1-}$ 248, BD-P9-1 ${ }^{76-347}$, BD-P9-1 167-347, BD-P9-1 198-347, BDP9- $1^{208-347}$ and BD-P9-1 ${ }^{76-207}$ were constructed. YTH results indicated that all deletions completely lost the ability to interact with P6 (Figure 7C). It is supposed that minor changes in the protein sequence might affect the properties and protein structure of P9-1 and thereby abrogate P6-P9-1 interaction. 

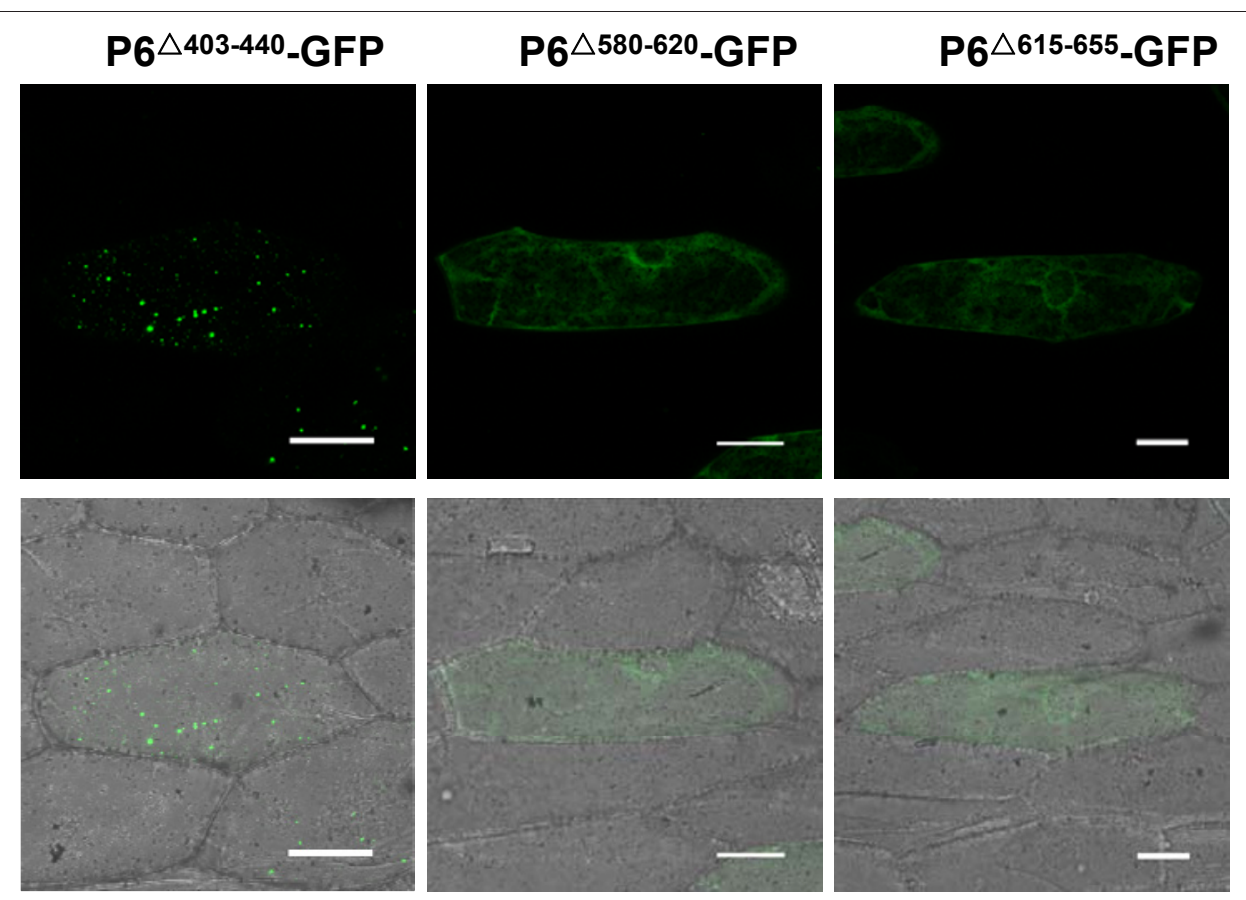

\section{DsRed-P6C $\triangle 403-440$}

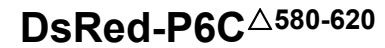

\section{DsRed-P6C $\triangle 615-655$}
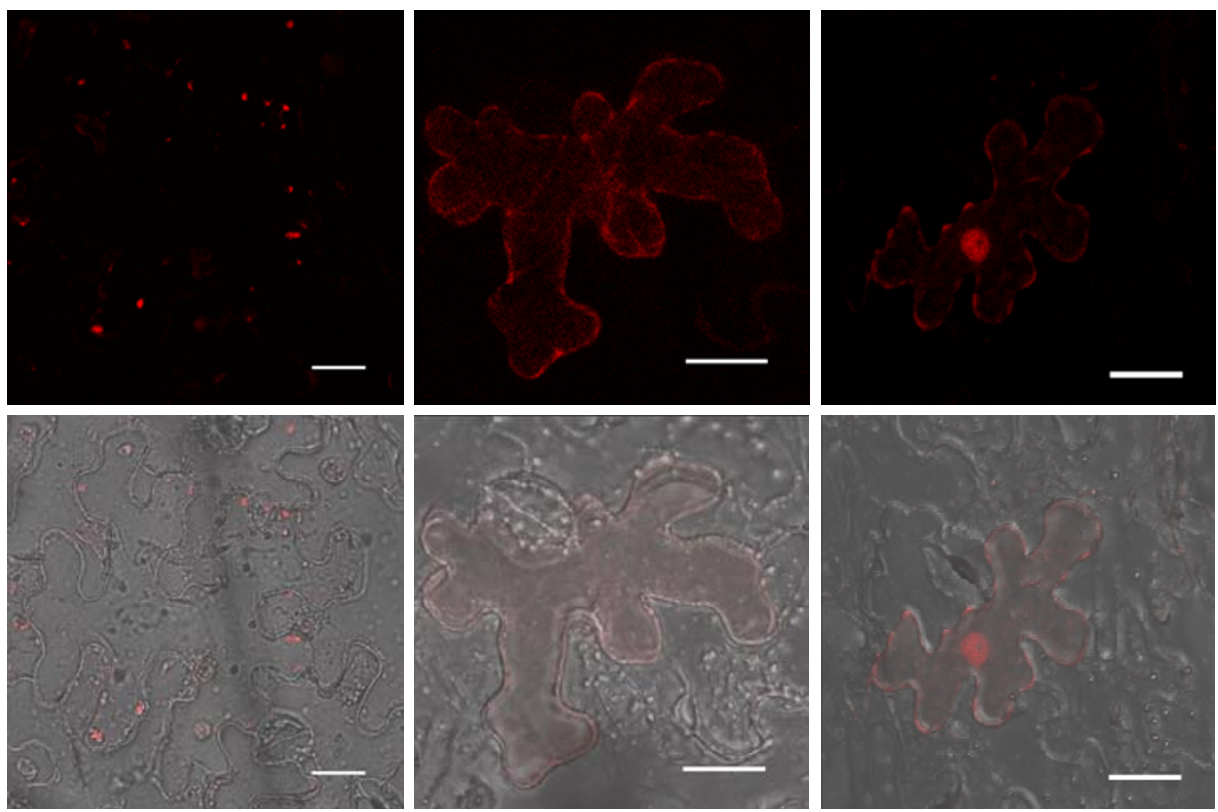

Figure 6 Transient expression results of P6 deleted derivatives. The upper two panels indicate the distribution of P6 deletions fused with GFP expressed in the onion epidermal cells, showing that $P 6^{\triangle 580-620}$-GFP and $P 6^{\Delta 615-655}$-GFP have a diffuse fluorescence pattern while $P 6^{\triangle 403-440}$ GFP forms numerous VLS. GFP was detected with excitation at $488 \mathrm{~nm}$ and emission capture at 550-590 nm. Bars, $20 \mu \mathrm{m}$. The lower two panels indicate the distribution of DsRed2-fused P6 deletions expressed in the epidermal cells of N. benthamiana leaves. Similarly, Both DsRed-P6C ${ }^{\Delta 580-}$ 620 and DsRed-P6C $C^{\Delta 615-655}$ show a diffuse and weak red fluorescence distribution whereas DsRed-P6C ${ }^{\triangle 403-440}$ forms VLS. Red fluorescence was 


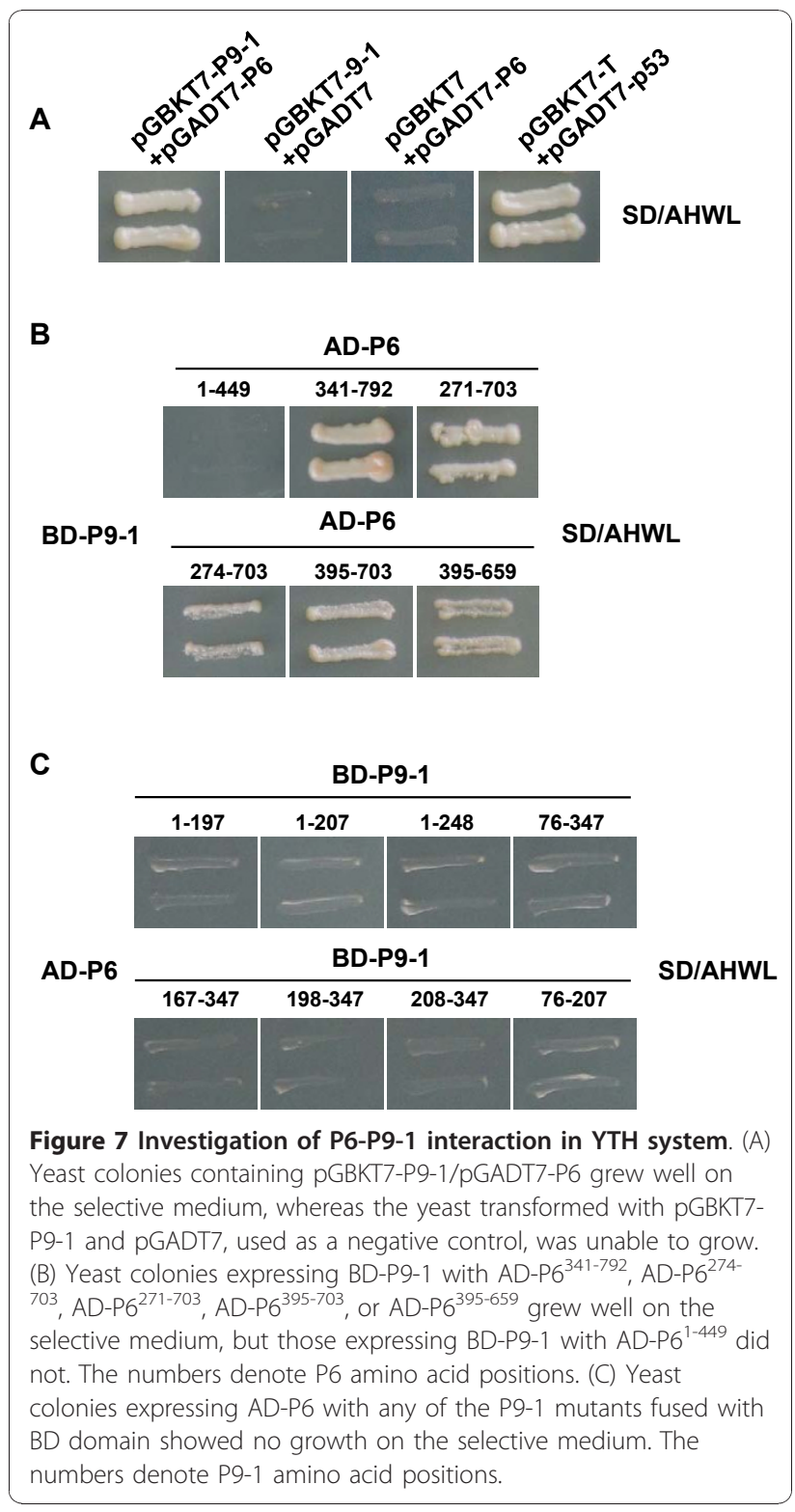

\section{Discussion}

Compared to animal reoviruses, most events in the Fijivirus life cycle, such as virus entry, replication, and packaging and particle assembly and systemic movement, are poorly understood, as are the functions of proteins encoded by the viral genome. In this study, we investigated the uncharacterized protein P6 of RBSDV, a member of the Fijivirus genus, by employing the related experiments in protein-protein interactions.

YTH analysis and/or subcellular localization experiments showed that P6 interact (Figure 2B) and establish punctate VLS when solely expressed in plant cells (Figure 1; Additional file 1, Figure S1), and BiFC assays also indicated that the truncated version $\mathrm{P}^{274-703}$ (equivalent to one-third of the whole P6 protein) is able to interact intimately to form aggregate-like structures (Figure 4). These results, which clearly demonstrated that P6 has a strong ability to self-assemble, prompted us to question whether P6 is capable of forming multimeric structures. Multimerization of viral proteins always plays an essential role in the virus cycle [20-22]. In Reoviridae, the viroplasm determinants, such as NSP2 and NSP 5 of rotaviruses, $\mu$ NS and $\sigma$ NS of orthoreoviruses, NS2 of orbiviruses, and Pns12 of rice dwarf virus, all share this characteristic to assemble into higher-order complexes to recruit other viral proteins or RNAs [23-29]. The self-interaction of RBSDV P6 might be prerequisite for its multimerization and subsequently for its biological functions.

The coiled-coil region might be involved in P6-P6 interactions. Coiled-coil motifs are increasingly recognized as key determinants in both intra- and inter-molecular interactions. In our experiments, the P6 region spanning residues 365 to 659 , which is predicted to harbour a coiled-coil structure and show some sequence homology with the ATPase domain of SMCs, is crucial for VLS formation. Deleting two peptide chains (aa 580620 and aa 624-654) abolishes VLS formation (Figure 6), which suggests that loss of this region might have a pronounced effect in altering the context of the whole protein and perturb the correct folding of the coiled-coil domain and thereby inhibit molecular interactions. On the basis of the different rates of yeast growth in the YTH assay and the different numbers of fluorescent foci formed in transient expression experiments, we conclude that, whereas the central region spanning residues 365 to 659 is identified as important for P6-P6 or P6P9-1 interactions, the amino acid sequences near to this region might also affect these interactions by changing the stability of the newly-built protein complexes.

A strong interaction between P6 and P9-1 was detected in our experiments. The two proteins are both expressed at high levels in infected plants and viruliferous insects, as detected by using antibodies against them $[8,17]$. Previous experiments indicated that the viroplasm matrix was densely and evenly immunolabelled with antibodies against P9-1 [8]. Although corresponding electron microscopy results have not been obtained for P6, the ability of P6 to form VLS and the heterologous interaction between P6 and P9-1, as well as the localization of P9-1 in hosts, hint that P6 might associate with viroplasm and play a role in the viroplasm nucleation. It is noteworthy that orthoreovirus $\mu \mathrm{NS}$, which plays an essential role in the process of viroplasm formation, is able to assemble into globular VLS when expressed alone and recruit another viroplasm-associated protein $\sigma \mathrm{NS}$ to the VLS $[24,30,31]$. This is quite similar to our results.

Despite the lack of detectable protein sequence homology with animal reovirus proteins, P6 possesses 
A
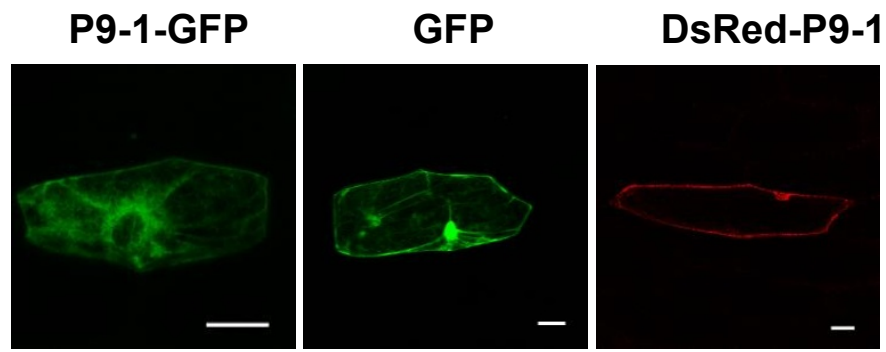

\section{DsRed2}

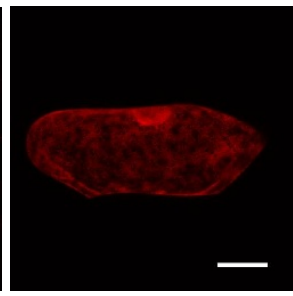

B

a

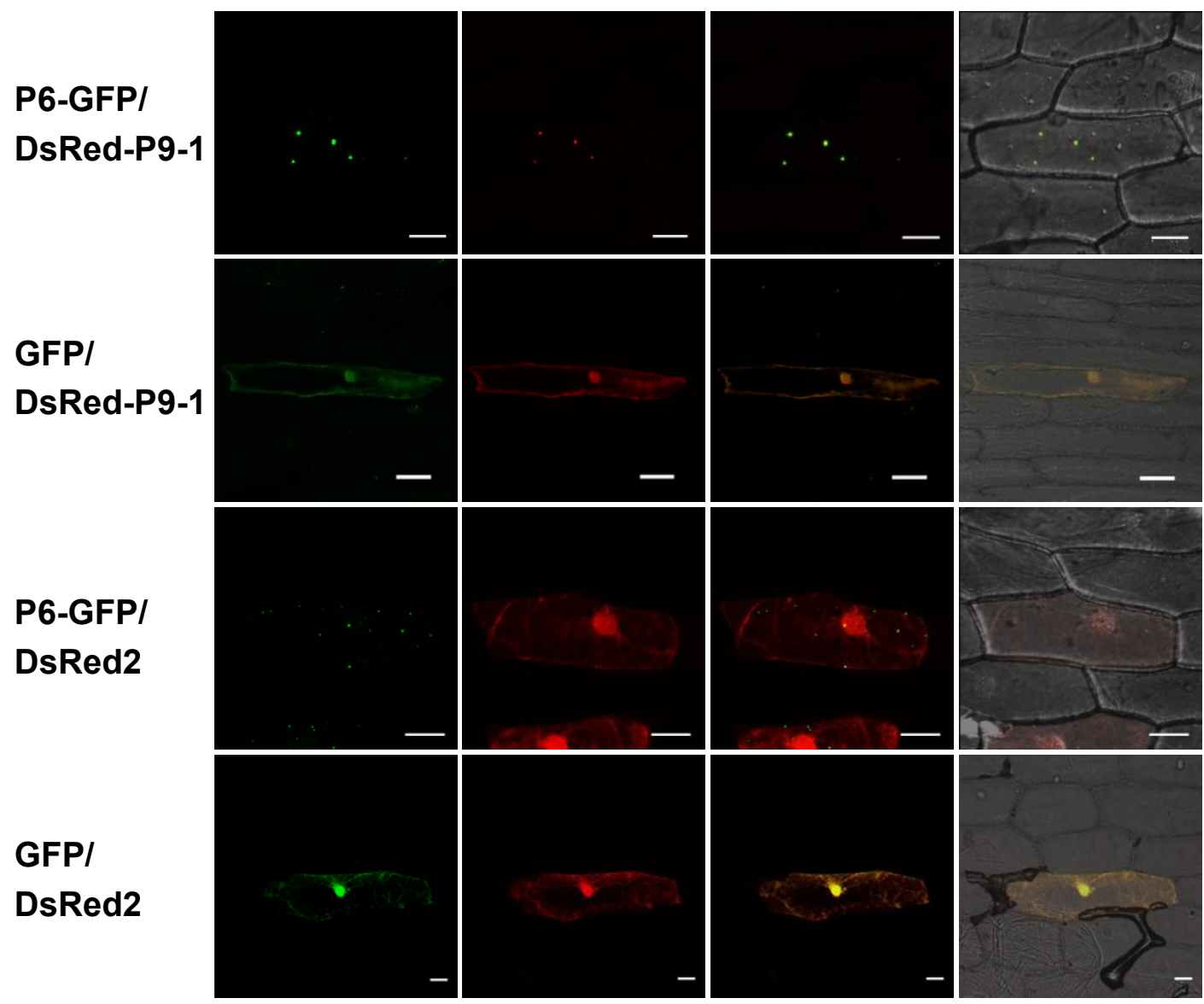

Figure 8 P6 is able to recruit P9-1 to VLS in onion epidermal cells. (A) Subcellular localization of P9-1 fused with GFP or DsRed2. P9-1-GFP and DsRed-P9-1 were distributed diffusely in the onion cells and were unable to form inclusion bodies. (B) Co-expression of P6-GFP and DsRedP9-1 in onion epidermal cells. Detection of green (lane a) and red (lane b) fluorescence was achieved with excitation at $488 \mathrm{~nm}$ and $543 \mathrm{~nm}$, respectively; co-localization of green and red fluorescence is indicated in yellow (lane c); superposition of the green and red fluorescence images as well as the bright field image is shown on the right (lane d). The co-expression results indicate that P6 was able to relocate the distribution of P9-1, that both proteins were present exclusively in the discrete and punctate foci, and that expression of DsRed2 or GFP had no aberrant effects on DsRed-P9-1 or P6-GFP distribution. Bars, 50 um. 
some common features with their viroplasm determinants. Being expressed at high level in hosts, possessing the ability to form VLS and recruiting the viroplasmassociated protein P9-1, P6 protein prediction showed that the P6 fragment located between amino acids 400 and 675 has a low homology with the SMC ATPase domain, whereas the region from positions 404 to 439 is likely to be a pumilio RNA-binding repeat profile, which indicates that P6 might be involved in ATP hydrolysis and binding of RNA. Generally, viroplasm determinants are often inferred to possess NTP-hydrolysis and RNAbinding activities to assist in the process of RNA replication, especially in Reoviridae [32,33]. It is necessary to do further work to elucidate the biochemical and biophysical properties of P6 and to determine whether P6 functions according to a mechanism that is similar to other viroplasm determinants of reoviruses in the process of viroplasm formation.

RBSDV P9-1 was previously reported to form inclusion bodies when tagged with GFP at its $\mathrm{C}$-terminus and expressed in Arabidopsis protoplasts [16], which is contrary to our findings. We investigated the P9-1 distribution by two different transient expression strategies. Whenever the protein is fused with GFP at its C terminus or DsRed2 at its $\mathrm{N}$ terminus and expressed in onion (Figure 8A) or tobacco epidermal cells or tobacco protoplasts (Additional file 3, Figure S3), P9-1 has a diffuse distribution pattern in the cytoplasm and cannot form aggregates. Consistent with the conclusion reached by Zhang et al [16], we confirmed that P9-1 self-interacts in the YTH system and forms stable dimers in vitro (data not shown). P9-1 itself might not be the nucleating factor in plant cells for it is located in the VLS only when coexpressed with P6.

Being highly homologous to RBSDV P9-1 (64.5\% identity) [34], Mal de Rio Cuarto virus (MRCV) P9-1, which was detected in viroplams in both infected plants and planthoppers [35], was found to be sufficient for the formation of viral inclusion body (VIB)-like structures when expressed in Spodoptera frugiperda Sf9 cells [36]. There might be distinct mechanisms involved in viroplasm formation in insect and plant hosts. These questions need to be addressed in future work.

\section{Conclusions}

This is the first report on the functionality of RBSDV nonstructural protein P6, which previously was completely uncharacterized. Our results showed RBSDV P6 self-interacts and forms punctate cytoplasmic VLS when expressed alone. Furthermore, P6 strongly interacts with the viroplasm-associated protein $\mathrm{P} 9-1$ and recruits $\mathrm{P} 9-1$ to localize in VLS. The P6 and P9-1 regions necessary for these homologous or heterologous interactions were also determined, as well as the exact residues essential for P6 VLS formation. Results presented here might provide clues for understanding the viroplasm nucleation of RBSDV and allow us to gain further insight into the relationship between P6 and P9-1 in the virus life cycle.

\section{Methods}

\section{General}

Healthy $N$. benthamiana plants were grown at $23{ }^{\circ} \mathrm{C}$ under 1,000 lumens with a 16-hour daylight regimen. Agrobacterium tumefaciens strain EHA105 was grown on LB agar containing $50 \mathrm{~g} / \mathrm{ml}$ rifampin. The yeast strains, Saccharomyces cerevisiae AH109 and Y187, and the yeast vectors, pGBKT7 and pGADT7, as well as the positive control plasmids, pGBKT7-T and pGADT7p53, were used for YTH analyses (Clontech). The binary expression vectors pGDR and pGDp19 used to express Tomato bushy stunt virus (TBSV) p19 for suppressing gene silencing were obtained as generous gifts from Professor Andrew O. Jackson of the University of California at Berkeley, USA, while another plasmid, pEGFP (Clontech) which harboured EGFP segment, was kindly provided by Professor Zaifeng Fan, China Agricultural University, PR China. BiFC vectors, pSPYNE-35S and pSPYCE-35S, were kindly provided by Professor Jörg Kudla, Universität Müneter, Germany. Both RBSDV S6 (GenBank: AY144570) and S9 (GenBank: AF536564) full-length cDNA clones were maintained in our lab [11].

\section{Construction of recombinant plasmids}

To generate transient expression vector pGFPI, pBI221 was digested with HindIII/XbaI and SacI/EcoRI respectively, and the liberated CaMV 35S promoter and nos terminator were ligated to $\mathrm{pUC18}$ - T corresponding clone sites to obtain an intermediate vector. EGFP encoding the autofluorescent protein was amplified using primers EGFP-1/EGFP-2 from plasmid pEGFP (clontech). PCR products were digested with $K p n \mathrm{I} / S a c \mathrm{I}$, and ligated into the KpnI/SacI-digested pUC18-T intermediate to generate pGFPI. Only the XbaI and KpnI can be used to express GFP-tagged protein in this vector. To generate expression recombinants for GFPtagged P6, full-length of P6 ORF was amplified using a pair of primers PS6-1/PS6-6 (Table 1). PCR products were ligated to pMD19-T to obtain pMD19-T-S6. pMD19-T-S6 was digested with BamHI/XhoI, and ligated into BamHI/XhoI-digested pSPYNE-35S. The

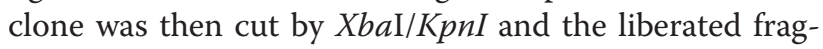
ment was ligated into the $X b a \mathrm{I} / K p n \mathrm{I}$-digested pGFPI to yield pS6GFPI, which can express P6-GFP. P6 deletion and truncation fragments were produced through PCR amplification, using the primers shown in Table 1 , and PCR products were ligated to PMD19-T or self-ligated 
Table 1 Primers used for PCR amplification

\begin{tabular}{|c|c|c|}
\hline Primer & Sequence $\left(5^{\prime} \rightarrow 3^{\prime}\right)^{\text {a }}$ & Locations ${ }^{b}$ and modifications \\
\hline PGFP-F & ggtacc ATGGGTAAAGGAGAAGAAC & 1aa;Kpnl \\
\hline PGFP-R & gagctc TTATTTGTATAGTTCATC & full-length reverse primer with stop codon; Sacl \\
\hline PS6-1-F & CG ggatcc ATGTCTGCCC & 1aa; BamHI \\
\hline PS6-4-F & CTAG ccatgg GA ATGTCTGCCCACCTGACCAATTTAG & 1aa; Ncol \\
\hline PS6-5-R & CG ggatcc TTACTCAGAGCTTAGTTGCCAGAGG & full-length reverse primer with stop codon; $\mathrm{BamHI}$ \\
\hline PS6-6-R & CCG ctcgag CTCAGAGCTTAGTTGCC & full-length reverse primer without stop codon; Xhol \\
\hline PS6-8-R & CCG ctcgag ATCAGCTACTTCGTCAG & 449aa; Xhol \\
\hline PS6-9-F & CG ggatcc AC ATGTCTGCCCACCTG & 1aa; BamHI \\
\hline PS6-10-F & CCG ctcgag ccatgg AAGCTTCTGATGTCCAG & 274aa; Xhol, Ncol \\
\hline PS6-11-F & CCG ctcgag ccatgg ACTTGATTAATCATGCC & 395aa; Xhol, Ncol \\
\hline PS6-12-R & CG ggatcc ggtacc ATCTCCAAAGTTAGCATCTAC & 703aа; BamHI, Kpnl \\
\hline PS6-15-R & CG ggatcc ggtacc CGTTTCATTAGCAGATGTTTTG & 659aа; BamHI, Kpnl \\
\hline PS6-16-R & TCC cccggg GAACAGATCGGCATGATTAATC & 403aa; Smal \\
\hline PS6-17-F & TCC cccggg GTGAATGATTTAACTGACGAAG & 440aa; Smal \\
\hline PS6-18-R & CATG gggccc GTCTTCTCTTITAGTAAAGAACAG & 615aa; Apal \\
\hline PS6-19-F & CATG gggecc TCTGCTAATGAAACGAATGATG & 655aa; Apal \\
\hline PS6-20-R & CATG gggecc GGCAATCTGTTCTTTAGCTTGTC & 580aa; Apal \\
\hline PS6-21-F & CATG gggccc GAGAACGAAATGTTGAAGGAACAG & 620aa; Apal \\
\hline PS6-24-F & GC tctaga ccatgg ACGTACTCAACCTGTCCAA & 98aa; Xbal, Ncol \\
\hline PS6-25-F & GC tctaga ccatgg AAGCTTCTGATGTCCAGTC & 274aa; Xbal, Ncol \\
\hline PS6-26-R & CCG ctcgag ggtacc CTCAGAGCTTAGTTGCCAGAG & full-length reverse primer without stop codon; Xhol Kpnl \\
\hline PS9-5-F & CTAG ccatgg GA ATGGCAGACCAAGAGCG & 1aa; Ncol \\
\hline PS9-6-R & CG ggatcc AACGTCCAATTTCAAGG & full-length reverse primer without stop codon; $\mathrm{BamHI}$ \\
\hline PS9-9-F & CG ggatcc ATGGCAGACC AAGAGCG & 1aa; BamHI \\
\hline PS9-10-R & CCG ctcgag AACGTCCAATTTCAAGG & full-length reverse primer without stop codon; Xhol \\
\hline PS9-11-F & CCG gaattc TCTCATCTCCCTAACC & 76aa; EcoRI \\
\hline PS9-12-R & CG ggatcc CAAATACATTAAAAAGCC & 207aa; BamHI \\
\hline PS9-13-F & CCG gaattc GGTGAAAATCCAAACTC & 208aa; EcoRl \\
\hline PS9-14-R & CG ggatcc GTGATTAACTTCTTATTTG & 248aa; BamHI \\
\hline PS9-15-F & CCG ctcgag CT ATGGCAGACCAAGAGCG & 1aa; Xhol \\
\hline PS9-16-R & ggtacc ggatcc TCAAACGT CCAATTTCAAG & full-length reverse primer, $\mathrm{Kpnl}, \mathrm{BamHI}$ \\
\hline PS9-17-F & gaattc gtcgac ATGGCAGACCAAGAGC & 1aa, EcoRl, Sall \\
\hline PS9-18-F & gaattc gtcgac ATGTCGTTGTTGCCAAT & 167aa, EcoRl, Sall \\
\hline PS9-19-F & gaattc gtcgac ATGTATATAAAAGGCTT & 198aa, EcoRl, Sall \\
\hline
\end{tabular}

${ }^{a}$ Introduced restriction endonuclease sites are in lower case. Two extra nucleotides (italicized) were added to allow in-frame expression of fusion proteins of interest.

${ }^{\mathrm{b}}$ Numbered according to P6 amino acid sequence. The F or R designation in the primer names denotes whether the primer is a forward ( $\left.5^{\prime}\right)$ or reverse ( $\left.3^{\prime}\right)$ primer, respectively.

to obtain intermediates selected for further use. The intermediates containing P6 truncation fragments $\left(\mathrm{P} 6^{274-792}, \mathrm{P}^{395-703}, \mathrm{P}^{395-659}\right)$ were digested with $\mathrm{XbaI} /$ $K p n \mathrm{I}$ and the liberated fragments were ligated into XbaI/KpnI-digested pGFPI to yield vectors expressing P6 truncations fused with GFP ( $\mathrm{P}^{274-792}$-GFP, $\mathrm{P}^{395-703}$ GFP, $\mathrm{P}^{395-659}$-GFP). As in the construction of pS6GFPI, similar strategies were used to obtain three P6 deletion derivatives (expressing P6 ${ }^{\triangle 403-440}$-GFP, $\mathrm{P} 6^{\triangle 580-620}$-GFP,
$\mathrm{P}^{\triangle 615-655}$-GFP) and pS9-1GFPI (expressing P9-1-GFP). For expression of the DsRed2-fused proteins, intermediates containing $\mathrm{P} 6$ truncation fragments $\left(\mathrm{P}^{274-792}\right.$, $\left.\mathrm{P}^{395-703}, \mathrm{P}^{395-659}\right)$ and those containing $\mathrm{P} 6$ deletion

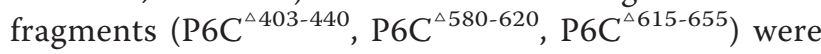
digested with XhoI/BamHI and HindIII/SalI, respectively, and the liberated fragments were ligated to the corresponding XhoI/BamHI- and HindIII/SalI-treated pGDR to generate vectors expressing P6 truncations and 
P6 deletions fused with DsRed2. A vector expressing DsRed-P9-1 was constructed similarly to those expressing P6 truncation fused with DsRed2.

To generate yeast plasmids for the two-hybrid assay, P6 ORF was amplified using primers PS6-4/PS6-5. PCR products were digested with $\mathrm{NcoI} / \mathrm{BamHI}$, and then ligated into the same sites of pGADT7 to generate pGADT7-S6. Vectors pGADT7-S9-1 and pGBKT7-S9-1 were created using similar strategies. P6 ORF was amplified using primers PS6-6/PS6-9 and the PCR products were ligated to pMD19-T. The clone was digested with BamHI/SalI, and P6 BamHI/SalI-fragments were ligated into the corresponding sites of pGBKT7 to obtain pGBKT7-S6. P6 NcoI/BamHI-fragments excised from the pMD19- $\mathrm{T}$ intermediates (containing $\mathrm{P}^{274-703}, \mathrm{P}^{395-}$ 703, $\mathrm{P6}^{395-659}$ ) were ligated into $\mathrm{NcoI} / \mathrm{BamHI}$ sites of pGADT7 and pGBKT7 to generate vectors expressing truncations fused with AD or BD. pGADT7-S6 was digested with EcoRI/BamHI and EcoRV, and the liberated fragments were ligated into pGADT7 EcoRI/BamHI and SmaI to obtain constructs expressing AD-P6 $641-792$ and AD-P6 $6^{271-703}$. P6 BamHI/XhoI-fragment from the intermediate harbouring $\mathrm{P}^{1-449}$ was inserted into the corresponding sites of pET30a, and then the clone was digested with $\mathrm{NcoI} / \mathrm{Xhol}$. The liberated fragment was cloned into the NcoI/XhoI-digested pGADT7 to obtain constructs expressing AD-P6 ${ }^{1-449}$. P6 NcoI/XhoI-fragments excised from the pMD19-T intermediates (containing $\mathrm{P}^{98-792}$ and $\mathrm{P}^{274-792}$ ) were ligated into the same sites of pGBKT7 to generate vectors expressing truncations BD-P6 ${ }^{98-792}$ and BD-P6 ${ }^{274-792}$. Similar strategies were used to generate the constructs expressing P91 mutants fused with BD.

To obtain construction binary vectors for BiFC, the intermediate which contained $\mathrm{P}^{274-703}$ was digested with $\mathrm{XbaI} / \mathrm{BamHI}$, and the $\mathrm{P} 6^{274-703}$ fragment was then inserted into the same sites of pSPYNE-35S and pSPYCE-35S to generate vectors expressing $\mathrm{P}^{274-703}$ $\mathrm{NE}$ and $\mathrm{P} 6^{274-703}-\mathrm{CE}$.

The primers used in the experiments are shown in Table 1. All clones derived from the PCR products were verified by sequencing, and the recombinant plasmids were confirmed by restriction analyses.

\section{YTH and $\beta$-galactosidase assays}

Yeast transformations were conducted using the smallscale lithium acetate method. Two-hybrid assays were performed using the Matchmaker GAL4 Two-Hybrid System3 (Clontech), according to the manufacturer's protocols. Cotransformants were plated on synthetic defined (SD) minimal medium minus adenine, histidine, leucine, and tryptophan (SD/-Ade/-His/-Leu/-Trp), and positive yeast colonies that could grow on the auxotrophic medium were lysed in liquid nitrogen and then tested for $\beta$-galactosidase activity as mentioned in the $\beta$-galactosidase colony-lift filter assay.

\section{Transient expression of protein in onion cells}

To introduce plasmid DNA into onion epidermal cells, particle bombardment was conducted using a heliumdriven particle accelerator PDS-1000/He (Bio-Rad). 2-5 $\mu \mathrm{g}$ plasmid DNA in $5 \mu \mathrm{L}$ distilled water were mixed with $8 \mu \mathrm{L}$ of a $60 \mathrm{mg} / \mathrm{mL} 1.0-\mu \mathrm{m}$-diameter gold particle solution, $20 \mu \mathrm{L}$ of $2.5 \mathrm{M} \mathrm{CaCl}_{2}$, and $8 \mu \mathrm{L}$ of $0.1 \mathrm{M}$ fresh prepared spermidine. The resultant suspension was incubated for $10 \mathrm{~min}$ with intermittent mixing every 1 to $2 \mathrm{~min}$ at room temperature. The golden particles coated with plasmid DNA were collected by 5 -s pulse centrifugation. After the supernatant was removed, the pellet was washed with $100 \mu \mathrm{L}$ of $70 \%$ cold ethanol followed by the same volume of $100 \%$ cold ethanol, and then suspended in $10 \mu \mathrm{L} 100 \%$ ethanol. After being dried on the center of an aluminum foil rupture disk, the gold particles were bombarded into onion cells under a vacuum of $28 \mathrm{~mm} \mathrm{Hg}$ with $6-\mathrm{cm}$ target distances. The bombarded onion epidermal cells were cultured on $0.6 \%$ agar with 2,4-D-free MS medium at $25{ }^{\circ} \mathrm{C}$ in darkness. Fluorescence signals were detected at 16 to $24 \mathrm{~h}$ after bombardment $[37,38]$.

\section{Subcellular localization of RBSDV P6 derivatives and BiFC assay in $N$. benthamiana leaves}

Different binary plasmids were transformed into $A$. tumefaciens EHA105 by a freeze-thaw method. Cultures of EHA105 harbouring a relevant binary plasmid were grown in LB medium containing rifampicin $(50 \mathrm{~g} / \mathrm{ml})$ and kanamycin $(100 \mathrm{~g} / \mathrm{ml})$ at $28{ }^{\circ} \mathrm{C}$ for $16 \mathrm{~h}$. For expression of different fusions, EHA105 strains containing the pGDR derivatives and pGDp19 plasmid were resuspended and adjusted to an $\mathrm{OD}_{600}$ of 0.5:0.3 with infiltration medium (10 mM MES, pH 5.6, $10 \mathrm{mM} \mathrm{MgCl}_{2}, 150$ $\mathrm{mM}$ acetosyringone). For the BiFC assay, Agrobacterium cultures containing the BiFC plasmids and the pGDp19 plasmid were resuspended at a final $\mathrm{OD}_{600}$ of 0.5:0.5:0.3. The cells were incubated at room temperature for 2 to $4 \mathrm{~h}$, and then infiltrated into 5-6-week-old N. benthamiana leaves. Underside epidermal cells of tobacco infiltrated leaves were assayed for fluorescence 48-96 h after infiltration [39].

\section{Laser-scanning confocal microscopy}

Fluorescence analysis was performed using a Nikon ECLIPSE TE2000-E inverted fluorescence microscope equipped with a Nikon D-ECLIPSE C1 spectral confocal laser scanning system. GFP and YFP were both detected with an excitation at $488 \mathrm{~nm}$ and emission capture at 550-590 $\mathrm{nm}$. DsRed2 was excited at $543 \mathrm{~nm}$ using a 543-nm helium neon laser, and the emission was 
captured at 570 to $600 \mathrm{~nm}$ [40]. For analysis of coexpression assays, multi-tracking was used to prevent emission cross-talk between the channels.

\section{Additional material}

Additional File 1: Transient expression of P6 fused with GFP in $N$. benthamiana protoplasts. Tobacco protoplasts were isolated and transfected using a modified PEG method. Punctata VLS of different sizes were prevalently formed in N. benthamiana protoplasts expressing P6GFP, while diffuse GFP fluorescence was observed in the nucleus and cytoplasm of the cells expressing free GFP. The results were observed 16 $\mathrm{h}$ after PEG transfection. Bars, $20 \mu \mathrm{m}$.

Additional File 2: Transient expression of P6 truncations fused with DsRed2 in $\boldsymbol{N}$. benthamiana protoplasts. DsRed-P6 ${ }^{274-792}$, DsRed-P6 ${ }^{395-}$ 703 and DsRed-P6 ${ }^{395-659}$ formed discrete bright aggregate-like structures in the $\mathrm{N}$. benthamiana protoplasts, while a weak and diffuse fluorescence was also detected in the cytoplasm. Free DsRed2 resulted in a diffuse pattern of fluorescence that was both nuclear and cytoplasmic. Bars, 20 $\mu \mathrm{m}$.

Additional File 3: Transient expression of DsRed-P9-1 and P9-1-GFP in $\mathbf{N}$. benthamiana cells or protoplasts. The plasmids expressing DsRed-P9-1 and P9-1-GFP were introduced into tobacco cells by agroinfiltration assay or PEG transfection, respectively. Both DsRed-P9-1 and P9-1-GFP resulted in a pattern of diffuse and uniform fluorescence distribution in the cytoplasm of $\mathrm{N}$. benthamiana cells or protoplasts, which indicated that P9-1 is unable to form aggregate-like structures when expressed alone in tobacco cells. Bars, $20 \mu \mathrm{m}$.

\section{Acknowledgements}

We are grateful to Professor Andrew O. Jackson (Department of Plant and Microbial Biology, University of California, Berkeley) and Sek-Man Wong (National University of Singapore, Singapore) for providing valuable suggestions. We also thank Professors Jörg Kudla (Universität Münster, Germany) for providing BiFC vectors. This research was supported by the National Basic Research Program (2006CB101903) and National Department Public Benefit Research Funds (nyhyzx07-051, 2008ZX08003-001 and 2009ZX08003-010B).

\section{Authors' contributions}

QW carried out most of the experiments and wrote the manuscript. TT and WW anticipated the construction of the recombinants. YZ provided useful advice and anticipated in the protein transient expression assays. CH, DL and $J Y$ conceived of the study and participated in its design and coordination. All authors read and approved the final manuscript.

\section{Competing interests}

The authors declare that they have no competing interests.

Received: 26 October 2010 Accepted: 18 January 2011 Published: 18 January 2011

\section{References}

1. Shikata E, Kitagawa Y: Rice black-streaked dwarf virus: its properties, morphology and intracellular localization. Virology 1977, 77:826-842.

2. Bai FW, Yan J, Qu ZC, Zhang HW, Xu J, Ye MM, Shen DL: Phylogenetic analysis reveals that a dwarfing disease on different cereal crops in China is due to rice black streaked dwarf virus (RBSDV). Virus Genes 2002, 25:201-206.

3. Fang S, Yu J, Feng J, Han C, Li D, Liu Y: Identification of rice blackstreaked dwarf fijivirus in maize with rough dwarf disease in China. Arch Virol 2001, 146:167-170.

4. Hibino H: Biology and epidemiology of rice viruses. Annu Rev Phytopathol 1996, 34:249-274.

5. Shikata E: Rice black-streaked dwarf virus. CMI/AAB description of plant viruses 1974:135.
6. Uyeda I, Kimura I, Shikata E: Characterization of genome structure and establishment of vector cell lines for plant reoviruses. Adv Virus Res 1995, 45:249-279.

7. Conti M, Lovisolo O: Tubular structures associated with Maize Rough Dwarf Virus particles in crude extracts: electron microscopy study. J Gen Virol 1971, 13:173-176.

8. Isogai M, Uyeda I, Lee BC: Detection and assignment of proteins encoded by rice black streaked dwarf fijivirus S7, S8, S9 and S10. J Gen Virol 1998, 79:1487-1494.

9. Milne RG, Conti M, Lisa V: Partial purification, structure and infectivity of complete maize rough dwarf virus particles. Virology 1973, 53:130-141.

10. Boccardo G, Milne RG: Plant reovirus group. CMI/AAB Descriptions of plant viruses 1984, 294.

11. Wang ZH, Fang SG, Xu JL, Sun LY, Li DW, Yu JL: Sequence analysis of the complete genome of rice black-streaked dwarf virus isolated from maize with rough dwarf disease. Virus Genes 2003, 27:163-168.

12. Zhang HM, Chen JP, Adams MJ: Molecular characterisation of segments 1 to 6 of Rice black-streaked dwarf virus from China provides the complete genome. Arch Virol 2001, 146:2331-2339.

13. Supyani S, Hillman BI, Suzuki N: Baculovirus expression of the 11 mycoreovirus-1 genome segments and identification of the guanylyltransferase-encoding segment. J Gen Virol 2007, 88:342-350.

14. Liu H, Wei C, Zhong Y, Li Y: Rice black-streaked dwarf virus minor core protein P8 is a nuclear dimeric protein and represses transcription in tobacco protoplasts. FEBS Lett 2007, 581:2534-2540.

15. Liu H, Wei C, Zhong Y, Li Y: Rice black-streaked dwarf virus outer capsid protein P10 has self-interactions and forms oligomeric complexes in solution. Virus Res 2007, 127:34-42.

16. Zhang C, Liu Y, Liu L, Lou Z, Zhang H, Miao H, Hu X, Pang Y, Qiu B: Rice black streaked dwarf virus P9-1, an a-helical protein, self-interacts and forms viroplasms in vivo. J Gen Virol 2008, 89:1770-1776.

17. Fang S, Wang Z, Han C, Li D, Yu J: Genomic segment 6 of Rice Black Streaked Dwarf Virus encodes for a viral non-structural protein. Acta Agriculturae Boreali-Sinica 2007, 22:5-8.

18. Hirano M, Hirano T: Hinge-mediated dimerization of SMC protein is essential for its dynamic interaction with DNA. EMBO J 2002, 21:5733-5744.

19. Goodin MM, Dietzgen RG, Schichnes D, Ruzin S, Jackson AO: pGD vectors: versatile tools for the expression of green and red fluorescent protein fusions in agroinfiltrated plant leaves. Plant J 2002, 31:375-383.

20. Haas G, Azevedo J, Moissiard G, Geldreich A, Himber C, Bureau M, Fukuhara T, Keller M, Voinnet O: Nuclear import of CaMV P6 is required for infection and suppression of the RNA silencing factor DRB4. EMBO $J$ 2008, 27:2102-2112.

21. Schuck P, Taraporewala Z, McPhie P, Patton J: Rotavirus nonstructural protein NSP2 self-assembles into octamers that undergo ligand-induced conformational changes. J Biol Chem 2001, 276:9679.

22. Nakai K, Okamoto T, Kimura-Someya T, Ishii K, Lim CK, Tani H, Matsuo E, Abe $T$, Mori $Y$, Suzuki $T$, et al: Oligomerization of hepatitis $C$ virus core protein is crucial for interaction with the cytoplasmic domain of E1 envelope protein. J Virol 2006, 80:11265-11273.

23. Taraporewala Z, Chen D, Patton JT: Multimers formed by the rotavirus nonstructural protein NSP2 bind to RNA and have nucleoside triphosphatase activity. J Virol 1999, 73:9934-9943.

24. Becker MM, Peters TR, Dermody TS: Reovirus $\sigma N S$ and $\mu$ NS proteins form cytoplasmic inclusion structures in the absence of viral Infection. J Virol 2003, 77:5948-5963.

25. Wei T, Shimizu T, Hagiwara K, Kikuchi A, Moriyasu Y, Suzuki N, Chen H, Omura T: Pns12 protein of Rice dwarf virus is essential for formation of viroplasms and nucleation of viral-assembly complexes. J Gen Virol 2006 87:429-438.

26. Jiang X, Jayaram H, Kumar M, Ludtke SJ, Estes MK, Prasad BV: Cryoelectron microscopy structures of rotavirus NSP2-NSP5 and NSP2-RNA complexes: implications for genome replication. J Virol 2006, 80:10829-10835.

27. Taraporewala ZF, Chen D, Patton JT: Multimers of the bluetongue virus nonstructural protein, NS2, possess nucleotidyl phosphatase activity: similarities between NS2 and rotavirus NSP2. Virology 2001, 280:221-231.

28. Butan C, Tucker P: Insights into the role of the non-structural protein 2 (NS2) in Bluetongue virus morphogenesis. Virus Res 2010, 151:109-117. 
29. Taraporewala ZF, Patton JT: Nonstructural proteins involved in genome packaging and replication of rotaviruses and other members of the Reoviridae. Virus Res 2004, 101:57-66.

30. Broering TJ, Parker JSL, Joyce PL, Kim J, Nibert ML: Mammalian reovirus nonstructural protein $\mu$ NS forms large inclusions and colocalizes with reovirus microtubule-associated protein $\mu 2$ in transfected cells. J Virol 2002, 76:8285-8297.

31. Miller CL, Broering TJ, Parker JSL, Arnold MM, Nibert ML: Reovirus oNS protein localizes to inclusions through an association requiring the $\mu \mathrm{NS}$ amino terminus. J Virol 2003, 77:4566-4576.

32. Vasquez-Del Carpio R, Gonzalez-Nilo FD, Riadi G, Taraporewala ZF, Patton JT: Histidine triad-like motif of the rotavirus NSP2 octamer mediates both RTPase and NTPase activities. J Mol Biol 2006, 362:539-554.

33. Gillian AL, Schmechel SC, Livny J, Schiff LA, Nibert ML: Reovirus protein oNS binds in multiple copies to single-stranded RNA and shares properties with single-stranded DNA binding proteins. J Virol 2000, 74:5939-5948.

34. Guzman FA, Distefano AJ, Arneodo JD, Hopp HE, Lenardon SL, del Vas M, Conci LR: Sequencing of the bicistronic genome segments $S 7$ and $S 9$ of Mal de Rio Cuarto virus (Fijivirus, Reoviridae) completes the genome of this virus. Arch Virol 2007, 152:565-573.

35. Guzman FA, Arneodo JD, Saavedra Pons AB, Truol GA, Luque AV, Conci LR: Immunodetection and subcellular localization of Mal de Rio Cuarto virus P9-1 protein in infected plant and insect host cells. Virus Genes 2010, 41:111-117.

36. Maroniche GA, Mongelli VC, Peralta AV, Distefano AJ, Llauger G, Taboga OA, Hopp EH, del Vas M: Functional and biochemical properties of Mal de Rio Cuarto virus (Fijivirus, Reoviridae) P9-1 viroplasm protein show further similarities to animal reovirus counterparts. Virus Res 2010, 152:96-103.

37. Kitajima A, Asatsuma S, Okada H, Hamada Y, Kaneko K, Nanjo Y, Kawagoe Y, Toyooka K, Matsuoka K, Takeuchi M, et al: The rice a-amylase glycoprotein is targeted from the Golgi apparatus through the secretory pathway to the plastids. Plant Cell 2009, 21:2844-2858.

38. Goodin MM, Austin J, Tobias R, Fujita M, Morales C, Jackson AO Interactions and nuclear import of the $\mathrm{N}$ and $\mathrm{P}$ proteins of sonchus yellow net virus, a plant nucleorhabdovirus. J Virol 2001, 75:9393-9406.

39. Walter M, Chaban C, Schutze K, Batistic O, Weckermann K, Nake C, Blazevic D, Grefen C, Schumacher K, Oecking C, et al: Visualization of protein interactions in living plant cells using bimolecular fluorescence complementation. Plant J 2004, 40:428-438.

40. Deng M, Bragg JN, Ruzin S, Schichnes D, King D, Goodin MM, Jackson AO: Role of the sonchus yellow net virus N protein in formation of nuclear viroplasms. J Virol 2007, 81:5362-5374.

doi:10.1186/1743-422X-8-24

Cite this article as: Wang et al.: Rice black-streaked dwarf virus P6 selfinteracts to form punctate, viroplasm-like structures in the cytoplasm and recruits viroplasm-associated protein P9-1. Virology Journal 2011

8:24.

\section{Submit your next manuscript to BioMed Central and take full advantage of:}

- Convenient online submission

- Thorough peer review

- No space constraints or color figure charges

- Immediate publication on acceptance

- Inclusion in PubMed, CAS, Scopus and Google Scholar

- Research which is freely available for redistribution

Submit your manuscript at www.biomedcentral.com/submit 